\title{
INCIDENCE OF ANEMIA BASED ON HAEMOGLOBIN LEVELS IN CHILDREN 2-12 YEARS OF AGED IN NOBEL MEDICAL COLLEGE TEACHING HOSPITAL, BIRATNAGAR, NEPAL
}

\author{
Amar Kumar Sinha And Biswajit Majumdar
}

\begin{abstract}
:
Haemoglobin levels were used to estimate the incidence of anaemia in children 2-12 years old in the population of Biratnagar,Morang Dist., Nepal. who were attending Nobel Medical College \& teaching hospital. Out of 5063 subjects, 634 children's were selectively diagnosed as anaemia. Among the 2406 children's aged 2-6 years 5.4\% were diagnosed with mild anaemia,2.7\% moderate anaemia and 1.7\% severe anaemia (WHO definition) of 2657 children's aged 7-12 years, $10.2 \%$ were diagnosed with mild anaemia, $3.1 \%$ moderate anaemia and $1.3 \%$ severe anaemia.
\end{abstract}

Kew Words: Incidence, Prevalence, Anaemia

\section{Introduction:}

Anaemia is the commonest problem in the growing age group in developing countries ${ }^{1}$. When iron deficiency is sufficient severe, $\mathrm{Hb}$ concentration in the blood decreases, leading to iron deficiency anaemia (IDA), which has negative health consequences, especially in children $^{3}$, adolescents ${ }^{4}$.

According to the latest data more than 3 billion people throughout the world have some form of anaemia ranging from deficiency in iron resources without symptoms of anaemia to iron deficiency anaemia. ${ }^{5}$ Iron deficiency in infancy and adolescence causes mental retardation and damages the immune system, predisposing children to a wide range of disorder. ${ }^{6,7}$ Different studies in $\mathrm{Egypt}^{8}$, India ${ }^{9}$, Thailand ${ }^{10}$ and the United states ${ }^{11}$ have shown that irondeficiency anaemia in children under 5 years old and primary school students is accompanied by psychomotor retardation, low intelligence and decreased learning capability. A study in Thailand has shown that the effects of anaemia on intelligence couldn't be compensated for ${ }^{10}$ one of the most dangerous consequences is the higher risk of poisoning with heavy elements, since the absorption of these elements increases in cases of iron deficiency. ${ }^{12}$ Recently it has been reported that preschool children have the highest prevalence of anaemia, nearly $50 \%$ across developing countries, compared with pregnant and non- pregnant women ${ }^{13}$

\section{Method and methodology:}

This retrospective study was conducted in Nobel Medical College \& Teaching Hospital ( NMCTH) with aim to serve Nepalese people. A sample size of 5063 subjects who were investigated for estimation $\mathrm{Hb}$ levels by Cyanmethaemoglobin method both aged 2-6 years and 7-12 years children.As anaemia is classified into three degree according to WHO: mild, moderate and severe. $\mathrm{Hb}$ cut-off values of anaemia for children $<6$ years were mild 10.0-10.9 g/dl, moderate 9.0-9.9 g/dl and severe $<9.0 \mathrm{~g} / \mathrm{dl}$. $\mathrm{Hb}$ cut- off of anaemia for children 6-12 years old were: mild 11.0-11.9 g/dl, moderate 10.0-10.9 g/dl and severe $<10.0$ $\mathrm{g} / \mathrm{dl}^{14}$ 


\section{Result:}

Table:1: shows that 634 subjects were diagnosed as anaemia out of a total population of 5063 including both the aged 2-6 years and 7-12 years childrens in our study. The total percentage of anaemia was $24.4 \%$ comparatively among them, 241 and 393 were 2-6 years and 7-12 years children respectively. The incidence of anemia was $9.8 \%$ in $2-6$ years and $14.6 \%$ in $7-12$ years children. The overall incidence of anemia was significantly higher $14.6 \%$ aged $7-12$ years of children.

Table: 2 reperesents the status of anaemia based on $\mathrm{Hb}$ levels measured in 2-6 years old children, severe anaemia was seen in $1.7 \%$, moderate anaemia was present in $2.7 \%$ and mild anemia was present in $5.4 \%$ of children . Overall incidence of anemia was $9.8 \%$.

Table 1: Incidence of anemia in both 2-6 and 7-12 years children

\begin{tabular}{|c|c|c|}
\hline $\begin{array}{c}\text { Total No of Investigated } \\
\text { Patients }\end{array}$ & Total Anaemic Patients & \% of Anaemic Patients \\
\hline 5063 & 634 & $24.4 \%$ \\
\hline
\end{tabular}

Table 2: Distribution of anaemia based on the $\mathrm{Hb}$ levels in children aged 2-6 years and 7-12 years of Nobel Medical College and teaching hospital, Biratnagar, Morang district of Nepal

\begin{tabular}{|c|c|c|c|c|}
\hline $\begin{array}{c}\text { Age group/severity of } \\
\text { anemia }\end{array}$ & No of patients & $\%$ & Total $\%$ & \\
\hline & *2-6 years & & & \\
\hline & $\begin{array}{c}\text { Severe } \\
\text { Moderate } \\
\text { Mild } \\
\text { Total }\end{array}$ & $\begin{array}{c}43 \\
66 \\
132 \\
2406\end{array}$ & $\begin{array}{c}1.7 \\
2.7 \\
5.4 \\
100.0\end{array}$ & 9.8 \\
\hline \multicolumn{5}{|l|}{$* * 6-12$ years } \\
\hline $\begin{array}{c}\text { Severe } \\
\text { Moderate } \\
\text { Mild } \\
\text { Total }\end{array}$ & $\begin{array}{c}36 \\
84 \\
273 \\
2657\end{array}$ & $\begin{array}{c}1.3 \\
3.1 \\
10.2 \\
100.0\end{array}$ & 14.6 & \\
\hline
\end{tabular}

Table: 2 also depicts the status of anemia based on haemoglobin $(\mathrm{Hb})$ levels, in children 7-12 years old. Severe anemia was seen in $1.3 \%$, moderate anemia was present in $3.1 \%$, Discussion:

Our retrospective study one of the hospital based study. The study shows that anaemia should be considered as a major health problem in Biratnagar, dist., Morang, Nepal. and mild anemia was present in $10.2 \%$ of children .The overall incidence of anaemia $14.6 \%$.So it is significantly higher than the 2-6 years of children

In total $9.8 \%$ of $2-6$ year old children and $14.6 \%$ of $7-12$ year-old children suffered from anaemia (Hbs $11.0 \mathrm{~g} / \mathrm{dl})$. According to the WHO classification if $5 \%-25 \%$ of the population have anaemia or abnormal $\mathrm{Hb}$, the degree of population anaemia is graded 


\section{Original article}

mild $^{7}$

A study in the United states (US) in 1976-80 showed the rate of anaemia to be around $6 \%$ in 2-6 year-old children. ${ }^{15}$ Anaemia is present in $27 \%$ of $1-6$ year- old children in the Philippines, $27 \%-44 \%$ in $3-5$ year- old children in India and $24 \%$ in $2-5$ year- old children in Romania. ${ }^{16}$ Another report showed that Asian children suffer from micronutrient deficiencies, especially iron deficiency anaemia and the prevalence of iodine- deficiency anaemia was $40-50 \%$ in preschool and primary- school children. ${ }^{17}$

\section{References:}

\section{De Maeyer E, Adiels-Tegman $M$.}

The prevalence of anaemia in the world. World Health Stat Q. 1985 38,302-316.

2. WHO U (1998). World Health Organization, UNICEF \& UNU Iron

Deficiency.Indicators for Assessment and Strategies for prevention 1998.

5. Michaelson KF et al, eds. Feeding And nutrition of infants and young children. Copenhagen, World Health Organization Regional Office for Europe, 2000,WHO European Series. N0. 87

6. Scrimashaw NS. Functional significance of iron deficiency: an overview. In: Enwonwu CO, ed. Functional significance of iron deficiency. Annual nutrition workshop series, Volume 111.

Nashville,Tennessee,Meharry Medical College, 1990:1-13.

7. Iron deficiency anaemia. Assessment, prevention and control. A guide for programme managers. Geneva, World Health Organization, 2001, $\mathrm{WHO} / \mathrm{NHD} / 01.3$

8. Seshadri S, Gopaldas T. Impact of Iron supplementation on cognitive functions in preschool and school aged children: the Indian experience. American journal of clinical nutrition, 1989, 50:675S-84S.

9. Soemantri AG. Preliminary finding on iron supplementation and Learning achievements of rural Indoesians childrens. American journal of clinical nutrition, 1989, 50:687S-96S.

\section{Anemia and it's Incidence}

The world Health organization has proposed that if the prevalence of anaemia in a region is between $5 \%$ and $20 \%$, appropriate interventions based on food diversification, food fortification, iron supplementation and controlling infectious diseases should be considered. ${ }^{7}$ Weekly iron supplementation for school children considered for primary schools. Fortification of foods (Such as iron fortification of biscuits) is another strategy which could be considered for preventing iron deficiency among Nepalese school children.

10. Pollitt E et al. Iron deficiency and educational achievement in Thailand. American journal of clinical nutrition, 1989, 50:687S-96S.

11. Pollitt E. Effects of a diet deficient in iron on the growth and development of preschool and school aged children. Food and nutrition bulletin, 1991, 13:110-18

12. Masawe MJ. The adverse effect of iron retention on the course of certain infections. British medical journal, 1987 , 2:1113-15.

13. Mason $\mathbf{J}$ et al. Recent trends in developing regions: vitamin A, anemia iodine deficiency and child underweight. Food and nutrition bulletin, 2005, 26(1):59-108.

14. Mohammed K, Malekafzali H. Nationl Health and Diseases Survey in the Islamic Republic of Iran. Tehran, Undersecretary for Reaserch, Ministry of Health and Medical Education, 1999.

15. Dallman PR,Yp R, Johnson C. Prevalence and causes of anemia in the United States, 1976 to 1980. American journal of clinical nutrition, 1984, 39:437-45.

16. Nestel P,ed. Proceeding: iron interventions for child survival. London, United States Agency for International development (USAID), Opportunities for Micronutrient Interventions (OMNI), and Institute for Child Health (ICH), 1995.

17. Khor GL. Update on the prevalence of malnutrition among children in Asia Nepal Medical College journal, 2003, 5(2):113-22.

Address for correspondence: Amar Kumar Sinha, Associate Professor, Department of Biochemistry, Nobel Medical College, Biratnagar, Morang., Nepal. E-mail: drak_sinha@yahoo.com 